\title{
História e formação do mercado das drogas*
}

\author{
History and Formation of the Drug Market
}

Cássio da Silva Calvete e Taciana Santos de Souza**

Resumo: Este trabalho discute a relação dos aspectos econômicos com o mercado de drogas ilícitas e a relação destes com as intervenções governamentais que buscam reduzir o custo social decorrente desse comércio ilícito. Para isso, é realizada uma revisão da história das drogas até o século XXI a partir da concepção marxista dos valores destas substâncias. O enfoque principal é para a história, a formação e as tendências atuais do mercado global de drogas.

Palavras-chave: Drogas. Economia da droga. Mercado de drogas. História das drogas

\begin{abstract}
This paper discusses the relationship between economic aspects and the drug market and their relationship with government interventions that aims to reduce the social cost of this illicit trade. For this, a review of the history of drugs is carried out until the 21 st century, based on the Marxist concept of the values of these substances. The main focus is around the history, training and current trends of the global drug market.
\end{abstract}

Keywords: Drugs; drugs economics; drug market; history of drugs; Cocaine

JEL: L19

\footnotetext{
* Submissão: 08/09/2019. Aprovação: 28/08/2020. DOI: http://dx.doi.org/10.5380/re.v41i76.69094.

** Respectivamente: (1) Professor do Departamento de Economia e Relações Internacionais da Universidade Federal do Rio Grande do Sul (UFRGS). E-mail: cassiocalvete@uol.com.br. ORCID: 00000002-2597-3066. (2) Bacharel em Economia pela Pontifícia Universidade Católica do Rio Grande do Sul (PUCRS), mestre em Desenvolvimento Econômico pelo Instituto de Economia da Unicamp (IE-Unicamp) e doutoranda em Desenvolvimento Econômico pela mesma instituição. E-mail: tacianass@gmail.com. ORCID: 0000-0003-1998-4145.
} 


\section{Introdução}

A problemática questão das drogas ilegais, tão presente na vida do homem contemporâneo, está entre as principais preocupações que assolam o mundo. Mesmo as pessoas que não vivenciam diretamente o problema são cercadas pelo assunto. Nos jornais, as drogas se mostram presentes nas notícias, sempre apresentadas em apreensões policiais ou em violências ocasionadas pela "guerra" ao tráfico. Nas ruas da maioria das capitais do país, usuários de drogas são vistos em situações degradantes. Nos diálogos, cidadãos comentam a violência gerada pelos assaltos, roubos e assassinatos, associados, muitas vezes, a usuários dessas substâncias.

É dessa forma que as drogas são comumente entendidas pelas pessoas como um problema social, gerador de violência, de desigualdade e de prejuízos à saúde. No entanto, antes de ser um problema social, a droga é, inicialmente, uma mercadoria.

Desse modo, a área da Ciência Econômica que se destinou para estudar este mercado clandestino denominou-se Economia das Drogas. O interesse pelo estudo da Economia das Drogas ocorre pela importância do tema. Além da criminalidade e da violência que se atribui a este comércio, o tráfico de drogas também abrange grande espaço geográfico e econômico. Do ponto de vista da Ciência Econômica, esse estudo também se justifica pela peculiaridade do produto comercializado e do mercado. Primeiramente, o tráfico de drogas apresenta características específicas de um comércio ilegal, com alto risco e com grande possibilidade de lucro. Além disso, o bem negociado é uma substância psicoativa que pode causar dependência e alterar o estado de consciência do indivíduo, modificando também a autonomia na decisão de compra do produto.

Portanto, esse caráter clandestino, o processo atípico de formação de preço do mercado produtor, as características alteradas e peculiares das decisões do mercado consumidor, bem como as ações da intervenção governamental, reprimindo o tráfico e interditando ou remediando as consequências do consumo, que explicam a curiosidade e a relevância do tema da Economia das Drogas.

Considerando essa preocupante situação, este trabalho pretende contribuir com o entendimento dos fatores econômicos vinculados ao mercado das drogas, que passaram por transformações ao longo da história. Nesse sentido, ressalta-se que, apesar de não serem levantadas as discussões sobre a viabilidade ou a possibilidade da legalização das drogas, entende-se que o conhecimento da história das drogas traz contribuição significativa a esse debate. 
Segundo o historiador espanhol Antonio Escohotado, o homem escolhe seu próprio "veneno" orientado pela tradição e pelos clichês, que desconsideram critérios racionais e farmacológicos e atribuem qualidades morais aos produtos químicos, definindo, assim, quais drogas são ou não aceitas na sociedade (ESCOHOTADO, 1995). Portanto, para compreender o problema social do tráfico e do consumo de drogas é necessário rever o passado e verificar como tudo começou. Desse modo, este artigo tem como objetivo responder a seguinte questão: como se deu a trajetória econômica das drogas na história, segundo a concepção marxista dos valores destas substâncias? Com o objetivo de respondêla e de contribuir para o debate econômico das drogas ilegais, este artigo apresentase em 4 sessões além desta introdução e das considerações finais. A primeira aponta os aspectos das ditas "drogas" enquanto valor de uso; a segunda revisa as transformações inerentes a esse produto que passou a representar um valor de troca; a terceira discute a droga enquanto mercadoria junto a todo contexto que desencadeia na proibição; a quarta, finalmente, apresenta um quadro do cenário econômico dessa mercadoria ilegal na contemporaneidade. Para isso, são utilizados materiais bibliográficos e banco de estimativas de dados do Escritório de Drogas e Crimes das Nações Unidas (UNODC).

\section{No princípio: a droga como valor de uso}

Ao longo do período que vai do século XVI ao XVIII, a palavra holandesa droog, que possivelmente deu origem à palavra "droga", era usada para se referir aos produtos naturais destinados à gastronomia e à cura de doenças (CARNEIRO, 2005). Segundo o Dicionário Aurélio, droga significa:

1. Med. Qualquer composto químico de uso médico, diagnóstico, terapêutico ou preventivo. 2. Restr. Substância cujo uso pode levar a dependência (4). 3. Substância entorpecente, alucinógena, excitante, etc. 4. Coisa de pouco valor ou desagradável (FERREIRA, 2000, p. 247).

De todos os significados citados no dicionário, o que não se aplica ao tema desta pesquisa é o exposto no item 4. De fato, as drogas, tanto legais quanto ilegais, não são "coisa de pouco valor". Elas estiveram presentes nas sociedades de organização primitivas, integrando festas, cultos e rituais religiosos (ESCOHOTADO, 1995). Também foram um dos bens mais disputados e cobiçados, nos séculos XVI e XVII, impulsionando as grandes descobertas e 
navegações nos novos continentes (CARNEIRO, 2005). A comercialização e a conquista de mercado para as drogas já ocasionaram guerras, como a Guerra do Ópio, na China, no século XIX (CÁRCERES, 1996).

Embora essas substâncias hoje instiguem, de modo geral, uma ideia negativa na sociedade, outrora, as drogas foram veneradas. A própria representação do vinho, por exemplo, como um deus, criado na figura de Dionísio (deus grego) e de Baco (deus romano), explicita bem o significado deste produto para o homem. A palavra grega methyein, que significa "embriagar-se", assim como a methíemi ("soltar, permitir"), referia-se às diversas drogas na sociedade antiga, assim como a esta bebida, que hoje é uma droga ainda aceita pelo homem. A própria Igreja exalta o vinho ao elevá-lo como símbolo do sangue de Cristo (ECOHOTADO, 1995; CARNEIRO, 2005).

Inicialmente, as drogas apresentavam sentidos social e sagrado. Eram utilizadas por terapeutas que, com um fundamento mágico, atingiam resultados eficazes na cura de doenças. Frente a uma epidemia, por exemplo, determinada comunidade optava pelo uso de ópio ${ }^{1}$, de heléboro ${ }^{2}$ ou de qualquer outro fármaco com propriedades curativas, para ser usado como remédio (ESCOHOTADO, 1995).

Além do uso farmacológico, os psicoativos também eram utilizados em festas. Os documentos antropológicos (e a própria atualidade) mostram a festa como sagrada para o homem, cuja necessidade de relaxamento e de escape da monotonia está associada a algum modo de transgressão periódica. Portanto, o indivíduo encontrava na festa "[...] uma renovação do mundo reforçada por acompanhamento de música, danças e algum fármaco.” (ESCOHOTADO, 1995, p. 49, tradução nossa ${ }^{3}$ ).

Ademais, as drogas estavam incluídas também nos rituais religiosos. A ingestão de caldo de tabaco iniciava as celebrações e os cultos na Bacia Amazônica e nas Antilhas; assim como o toloache ${ }^{4}$, na América Central; o kawa-kawa ${ }^{5}$, na Oceania; e o iboga ${ }^{6}$, na África (ESCOHOTADO, 1995). Nas comunidades xamanísticas, as drogas aproximavam as entidades espirituais do xamã, que

\footnotetext{
${ }^{1}$ Substância extraída da papoula, utilizada na produção de heroína.

2 Planta tóxica usada para fins homeopáticos.

${ }^{3}$ No original: “[...] una renovación del mundo reforzada por el acompañamiento de música, danzas y algún fármaco".

${ }^{4}$ Datura inoxia.

${ }^{5}$ Planta terapêutica, usada como calmante.

${ }^{6}$ Raiz de planta alucinógena. A ibogaína está sendo pesquisada para tratamento de dependência química.
} 
encontrava na meditação, no jejum ou na ingestão de substâncias psicoativas, o caminho para abandonar seu corpo, transformar-se em espírito e viajar "[...] em direção a uma realidade extraordinária para ajudar os membros de sua comunidade" (MacRAE, 1992, p. 18). Assim como a figura do xamã, que surgiu na Ásia Central e se estendeu à América e à Europa, o "feiticeiro de possessão" fazia uso de substâncias semelhantes, mas com a intenção de ser raptado por entidades espirituais (ESCOHOTADO, 1995).

Até hoje algumas religiões utilizam enteógenos (como preferem chamar) nos seus rituais, como é o caso da ayahuasca, que é bebida pelos seguidores da Doutrina do Santo Daime ${ }^{7}$ (A DOUTRINA, 2011). A palavra enteógeno, do grego entheos, significa "deus dentro" e explica a condição de uma pessoa que recebeu um deus ou teve uma entidade tomada por seu corpo, dando, assim, um aspecto divino a determinadas substâncias alucinógenas (MacRAE, 1992).

Portanto, entende-se que, no princípio, as drogas tinham um significado um pouco diferente do que têm hoje. Acompanhavam a organização socioeconômica da época, eram um bem coletivo e não ocasionavam qualquer problema social. Embora úteis para a comunidade, não representavam valor econômico, isto é, as drogas agregavam somente valor de uso. Conforme Marx $^{8}$, a utilidade de um bem advém das propriedades físicas dele e da grande capacidade de serventia deste produto, destacando-o pelo seu valor de uso (MARX, 1982). Assim, era essa a representatividade das drogas até a Idade Antiga.

\section{A droga: do valor de uso ao valor de troca}

Com a consolidação do mercantilismo, que acarretou na centralização do poder, na formação dos estados nacionais e na assiduidade do comércio e das trocas de produtos entre os povos distantes, as drogas ganharam um novo papel. Conforme os relatos do jesuíta André João Antonil, autor do livro "Cultura e opulência do Brasil por suas drogas e minas", escrito em 1711, as hoje chamadas especiarias, que eram as conhecidas drogas da época, estimularam as grandes navegações. A partir desse período, as drogas tornaram-se, então, mais relevantes,

\footnotetext{
${ }^{7}$ A Doutrina do Santo Daime foi fundada em Rio Branco, no Acre, por volta de 1930, pelo Mestre Irineu ou Raimundo Irineu Serra, ex-cabo da Guarda Territorial, que teve contato com comunidades indígenas da Amazônia brasileira, peruana e boliviana (MacRAE, 1992).

${ }^{8}$ Para maiores detalhes sobre a história das drogas sob o ponto de vista marxista, recomenda-se a leitura de Lima (2009).
} 
alcançando um significado mais sofisticado e excêntrico. Esse novo conceito estava associado não só às propriedades medicinais, mas também à alimentação, já que "[...] a época colonial pode ser incluída entre as sociedades que não fazem uma distinção precisa entre droga e comida [...]" (CARNEIRO, 2005, p. 14), por ser um instrumento de alívio da dor (física e psíquica) e uma fonte direta de prazer (CARNEIRO, 2005).

Assim, esses bens eram predominantes entre o conjunto de produtos trocados nas expedições marítimas. A produção e o consumo de bebidas alcoólicas (destiladas e fermentadas) predominavam no comércio europeu, assim como o tabaco, o ópio ou o café, na América, na Ásia e na África. O tabaco e a aguardente, por exemplo, eram os principais produtos utilizados pelo Brasil na compra de escravos africanos (CARNEIRO, 2005). Assim, as drogas, durante a Idade Moderna, acrescentaram um valor comercial, cuja troca permitia circulação de mercadorias entre diferentes Estados, agregando a estes bens um valor de troca.

Pelo significado marxista, a diferença entre valor de uso e valor de troca se explica quando:

\footnotetext{
Um homem que, com seu produto, satisfaz suas necessidades pessoais produz um valor de uso, mas não uma mercadoria. Para produzir mercadorias é preciso que não se produzam apenas simples valores de uso, mas valores de uso para outrem, valores de uso sociais (MARX, 1982, p. 27-28).
}

Conforme essa definição, a partir do mercantilismo, as drogas transpuseram da utilidade de uma comunidade primitiva, de um uso local, limitado a uma cultura, para um uso mais expansivo e abrangente, qualificando-se pelo uso social (e não apenas local), acarretando trocas comerciais e, consequentemente, agregando valor econômico. Por fim, a droga transformou-se em mercadoria.

Como o comércio de psicoativos expandiu-se por todos os continentes, firmaram-se os hábitos de consumo no homem. Enquanto a droga distinguia-se apenas por seu valor de uso, não se podia associar a ela a ideia de problema social (LIMA, 2005). Em princípio, um problema social refere-se a uma realidade, mutável conforme a época e a região, que se estabelece por fenômenos instituídos, que são investigados, principalmente, pelas ciências humanas (LENOIR, 1998 apud FIORE, 2005). A partir do momento em que ocorre disputa pelo mercado e domínio de produção das drogas iniciam os primeiros conflitos relacionados a esta mercadoria. 
Essa busca intensa por mercados consumidores é bem caracterizada pelo comércio de ópio no Oriente. Esse psicoativo, que era usado na Ásia milênios antes de Cristo, conhecido como a "planta da alegria", era utilizado como alimento, sendo ingerido como comida. Porém, a partir do final do século XVII, a planta passou a ser fumada, forma pela qual causa maiores prejuízos à saúde. Concomitantemente, a Índia expandia a produção de ópio e difundia o seu uso pelo Oriente. Devido ao aumento da demanda, principalmente pelo excesso de importações chinesas da droga, e aos danos causados pela nova forma de consumo, pois o fumo do ópio incluía o tabaco, o imperador chinês Yongzheng proibiu, em 1729, a importação e a venda de ópio na China. Mais tarde, outras nações como Mianmar, Tailândia, Vietnã e Indonésia, também baniram a droga (UNODC, 2008). Porém, mesmo com a repressão, o consumo não cessou de crescer.

Nas terras indianas, a produção desse psicoativo se dava em grandes escalas. A British East India Company, companhia inglesa que se estabeleceu na Índia durante a colonização, mantinha o monopólio da produção e da venda de ópio. Antecipando-se da possível concorrência de outros produtores, como a Turquia e a Pérsia, a companhia inglesa cresceu rapidamente. As terras indianas usadas para cultivo da planta passaram de 36 mil hectares, em 1830, para 71,2 mil, em 1840, e para 200 mil hectares, em 1900. O aumento da oferta acarretou queda drástica nos preços. Por isso, o custo de um lote ${ }^{9}$, que, em 1822, era 2,5 mil dólares, reduziu, em 1838, para 585 dólares (UNODC, 2008).

Essa redução dos preços contribuiu ainda mais para a popularização da droga, que se caracterizou pelo consumo em massa, como pode ser observado no Erro! Fonte de referência não encontrada. que mostra a evolução da importação de ópio na China, que era o principal importador de ópio da Inglaterra:

\footnotetext{
${ }^{9} 1$ lote equivale a $63,5 \mathrm{~kg}$.
} 


\section{Gráfico 1 - Evolução das importações chinesas de ópio (1650-1880)}

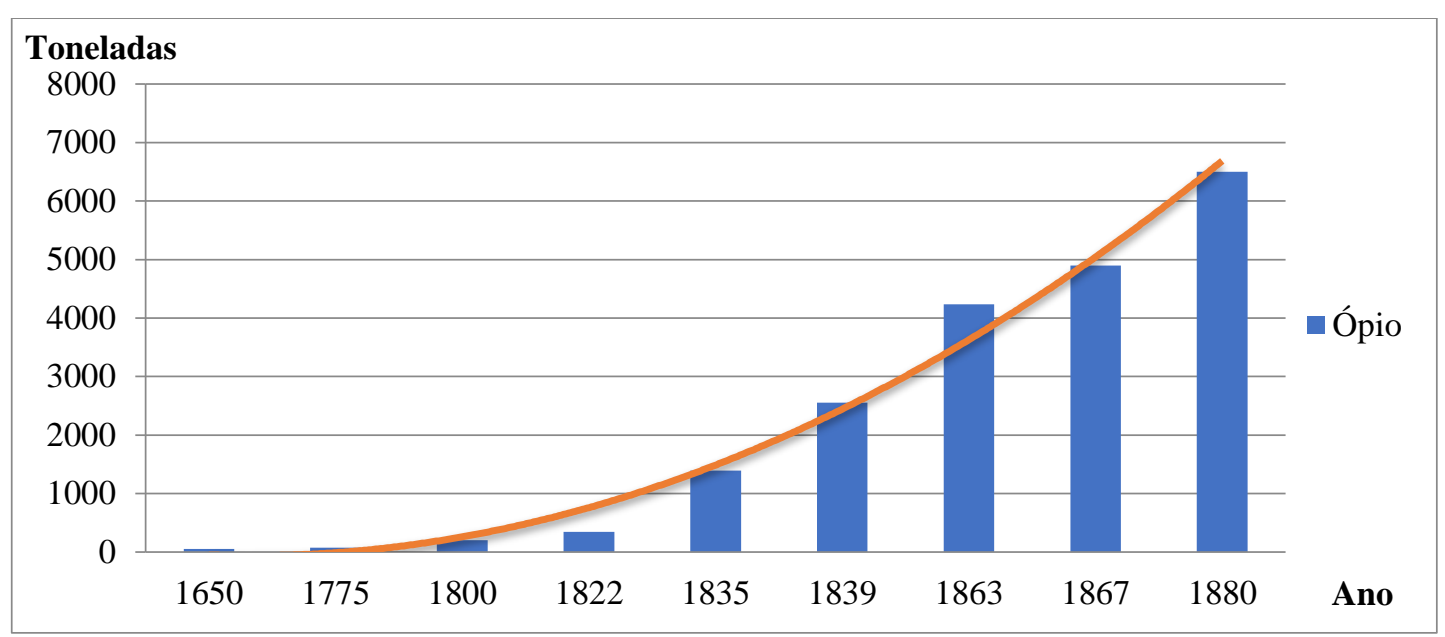

Fonte: UNODC (2008).

Devido ao crescimento do contrabando sino-inglês, o imperador chinês resolveu reforçar a repressão, banindo a entrada dos navios ingleses nos portos e apreendendo todas as drogas, iniciando a Guerra do Ópio, na China. Como a British East India Company estava militarmente preparada, pois possuía armas e estruturas de defesa, não só para uma possível guerra, mas também para ataques de piratas, venceu a Guerra. Assim, a China teve de assinar, em 1842, o Tratado de Nanking, cujas consequências foram a posse de Hong-Kong ao controle inglês, a abertura de mais cinco novos portos ao comércio do ópio e o pagamento de uma alta indenização pelos chineses (UNODC, 2008).

Portanto, foi com a vitória inglesa que o domínio do ópio se firmou. Segundo os dados da Delegação Chinesa, debatidos em 1909, na Conferência de Xangai sobre o Ópio, houve um incremento, em 1906, de cerca de 21,5 milhões de consumidores. No início do Século XX, os chineses participavam de $85 \%$ a $95 \%$ do consumo mundial da droga que, segundo o relatório "100 Anos do Controle de Drogas", nas Nações Unidas: "Nunca antes o mundo teve tal conhecimento sobre problemas com drogas nesta escala e intensidade" (UNODC, 2008, p. 177, tradução nossa $\left.{ }^{10}\right)$.

Enquanto o Oriente sofria as consequências da colonização inglesa e do monopólio do ópio, no Ocidente esse comércio difundia-se de modo diferente. As drogas não eram tão populares e vendidas em grandes escalas ou a todas as classes

\footnotetext{
${ }^{10}$ No original: "Never before or since has the world known a drug problem of this scale and intensity."
} 
sociais, como na China. Na Europa, os principais consumidores de ópio eram os grupos de intelectuais e de artistas, que se reuniam em locais próprios para fumála, nas ditas fumeries (LIMA, 2005). Não é à toa que esse psicoativo influenciou o romantismo alemão ${ }^{11}$, destacando como usuários personalidades como Goethe, Delacroix, Goya, Tolstoi, entre outros autores de várias nacionalidades (ESCOHOTADO, 1995, v. 2). Somente no século XIX ocorreria a popularização dos opiáceos que, então, seriam associados, juntamente ao álcool, ao uso problemático, como bem descreveu Engels (1845), em "A situação da classe operária na Inglaterra", ao contextualizar a situação degradante dos trabalhadores nos grandes centros urbanos e industriais.

De fato, o ópio ainda não enfrentava preconceitos e tinha grande aceitação na população europeia, que já mostrava problemas com o alcoolismo, um tema muito estudado pela psiquiatria na época. Devido a isso, em 1751, a Inglaterra promulgou o Gin Act, um ato pelo qual estabelecia restrições e altas taxas sobre a produção e o comércio desse destilado, implicando, assim, o crescimento da indústria da cerveja (ESCOHOTADO, 1995).

Todavia, as drogas, que já haviam conquistado seu papel no mercado, ainda se apresentavam de modo natural, no período mercantilista. No entanto, a partir do século XIX, o desenvolvimento da química destacou os alcalóides, possibilitando o isolamento e a extração das substâncias psicoativas das plantas naturais (LIMA, 2009 , p. 43-44). A primeira delas foi a morfina ${ }^{12}$, obtida no ópio, em 1804, pelo farmacêutico alemão Friedrich Serturner (ESCOHOTADO, 1995, v. 2). Desse modo, essa evolução na ciência, permitiu desmistificar a natureza e reunir "[...] ao médico uma aura mágica, principalmente com o uso dos analgésicos e dos anestésicos e em especial com o uso da morfina" (ADIALA, 1996, p. 37-38 apud LIMA, 2009, p. 44).

Em seguida, surgiu a diacetilmorfina, derivada da morfina, em 1874, registrada com o nome de heroína, em 1898, pela indústria farmacêutica alemã Bayer. O nome assim batizado foi uma referência à palavra alemã heroisch (heróico), por caracterizar, assim, os efeitos estimulantes e analgésicos do, então, fármaco (ESCOHOTADO, 1996). Phármakon é um vocábulo grego, que significa

\footnotetext{
${ }^{11}$ Movimento artístico de oposição às ideias iluministas e modernas. Buscava-se, por meio da literatura, música e pintura, retomar as emoções e os sentimentos dos homens, como oposição aos valores da razão.

${ }^{12}$ Nome em homenagem a Morfeu, deus grego do sono.
} 
tanto remédio como veneno (ESCOHOTADO, 1995, v.1). Essa ambiguidade é bem percebida ao verificar o uso da heroína nos tratamentos para recuperação dos ditos "toxicômanos viciados" em ópio e em morfina. Essa serventia da droga hoje tida como uma das mais perigosas - como medicamento emerge uma discussão sobre a problemática questão do que separa uma droga de um fármaco.

\begin{abstract}
A indústria Bayer foi uma das empresas que, na primeira conferência internacional da área de drogas, a de Xangai, em 1909, esteve atenta para evitar, de qualquer forma, ser a heroína colocada na lista de substâncias perigosas. Até próximo de 1902, seu emprego "terapêutico" e a ausência de financiamento para estudos rigorosos sobre seus efeitos, permitiram sua distribuição comercial para toda a Europa, aos Estados Unidos e até a China, em torno de 3.000 pontos de vendas (KOUTOUZIS; PEREZ, 1997, p. 42 apud LIMA, 2005, p. 89).
\end{abstract}

Se, por um lado, o desenvolvimento da indústria química e farmacêutica implicou avanços na medicina e melhorias na saúde do homem; por outro, contribuiu para o monopólio e o domínio da mercadoria. Durante o século XIX, surgiram as grandes indústrias farmacêuticas (que permanecem na atualidade), como a Bayer, a Hoechst, a BASF, a Roche, a CIBA e a Sandoz (LIMA, 2005).

De fato, esse avanço científico contribuiu para a disseminação de diversas drogas. Além das citadas heroína e morfina, foi neste contexto de pós-revolução industrial e de consolidação da economia capitalista, que apareceu a cocaína. A folha de coca era utilizada desde 2500 a.C. pelos incas (LEITE; ANDRADE, 1999; LIMA, 2005). Culturalmente, a folha é mastigada, o que proporciona aos nativos suportar a falta de oxigênio comum em regiões de grandes altitudes, como a região dos Andes. Além disso, a colonização espanhola explorou os índios que, com trabalho escravo, encontravam na coca mascada um suprimento à fome, ao cansaço e ao frio, pois a planta tem propriedades estimulantes. Esse hábito não se difundiu entre os espanhóis, visto que estavam mais interessados na prata e nas minas andinas e não tinham a mesma habilidade dos índios em mascar as folhas e alcançar os mesmo efeitos (ESCOHOTADO, 1996; LEITE; ANDRADE, 1999; LIMA, 2005; DOMANICO, 2006).

Porém, em 1859, o químico alemão Albert Nieman extraiu o alcalóide cocaína $^{13}$ das folhas de coca após uma expedição austríaca que levou a planta andina à Europa em 1882 (ESCOHOTADO, 1995). A descoberta da substância, a

${ }^{13} \mathrm{C}_{17} \mathrm{H}_{21} \mathrm{NO}_{4}$ 
princípio, não acarretou aumento na demanda. No entanto, em 1884, o químico alemão conseguiu comprovar as propriedades anestésicas da substância, crescendo, dessa forma, a demanda pela droga, que não se popularizou rapidamente devido aos preços altos (NEVINNÝ, 2003).

Ainda assim, desde o início, o comércio dessa droga foi globalizado. Ao contrário do que se pensa, não foi na Colômbia que se formou o primeiro cartel de coca, mas na Suíça. Segundo Karch, as indústrias farmacêuticas europeias pretendiam, através do cartel, manipular o mercado da droga com o propósito da legalização das vendas (KARCH, 2003), visto que a cocaína desempenhava um papel importante no homem, pois era um estimulante em potencial, sendo usada, inclusive, por soldados alemães durante a II Guerra Mundial (DOMANICO, 2006). A substância também esteve presente na fórmula da bebida Coca-cola ${ }^{14}$, que era uma forte concorrente dos Estados Unidos com relação às grandes indústrias alemãs (GOOTENBERG, 2008). Entre diversos cientistas e pesquisadores, Freud, o pai da psicanálise, foi um dos principais adeptos da cocaína, utilizando-a em tratamentos de pacientes (GOOTENBERG, 1999).

A cocaína alcançou sua glória devido aos efeitos excitantes e eufóricos que causam no ser humano e também pela variedade de formas de consumo - podendo ser inalada, injetada ou fumada. Embora a droga tivesse passado por todos os continentes, não chegou a ser considerada uma "epidemia" como o ópio, por exemplo, pois o consumo do "pó" não pertenceu às cestas de bens das camadas sociais mais baixas. Para tais classes, surgiram novos produtos derivados da coca, como o crack.

A inserção dessas substâncias psicoativas no mercado, tais como mostradas no exemplo do álcool, do ópio e da cocaína, atribuíram um significado muito comercial a esses produtos. Entretanto, as peculiaridades farmacêuticas, sociológicas e culturais dos diferentes contextos que norteiam esse mercado (do consumo abusivo à abstinência) serviram como justificativa para o início da proibição da mercadoria, que também esteve pautada em interesses econômicos.

\footnotetext{
${ }^{14}$ Nessa época, a Coca-cola era vendida em farmácias, sendo utilizada como remédio (uma espécie de xarope estimulante).
} 


\section{A droga: da mercadoria à proibição}

Entre meados do século XIX e o início do XX, drogas como a cocaína e outras derivadas do ópio eram amplamente consumidas em todo planeta. As indústrias farmacêuticas europeias e o monopólio britânico de ópio formavam pontos geograficamente estratégicos de domínio econômico e político, que se mantinham no comércio legal desses bens. No entanto, a partir do século XX, iniciou-se uma discussão acerca da nocividade dessas substâncias. A Conferência de Xangai sobre o Ópio, de 1909, não estabeleceu interdições, mas realizou o primeiro debate sobre o controle do mercado de psicoativos (RODRIGUES, 2005).

A questão da proibição das drogas foi uma iniciativa dos Estados Unidos e se consolidou no clima da política do presidente Roosevelt (Big Stick) que lhes delegava a missão "caridosa" de interferir nos países latino-americanos, ajudandoos a manter autonomia frente ao domínio europeu (SCHILLING, 2002). Essa luta contra as drogas também foi apresentada na Conferência de Xangai, quando se incumbiu aos Estados Unidos a tarefa de "salvar" o povo asiático que sofria dos males causados pelo mercado do ópio. Nesse período, impedir o comércio de psicoativos representava, sobretudo, contrariar a supremacia geográfica e econômica da Europa.

Além dos interesses diplomáticos, havia ainda outras justificativas para essa posição. Para o sociólogo estadunidense Howard Becker (1977), os princípios da proibição de psicoativos na cultura dos Estados Unidos poderiam se explicar em três razões principais: a religião protestante, o utilitarismo e o humanitarismo. A ética protestante não aprova o descontrole e a irresponsabilidade; logo, o indivíduo em estado de embriaguez ou de alucinação, perderia o autocontrole e a responsabilidade, agindo de forma não apropriada segundo os fundamentos da Igreja. Outro fator está associado a questões culturais que desaprovam que o indivíduo tome ações exclusivamente para obtenção de prazer; a população norteamericana age de forma mais pragmática, evitando que o objetivo de determinada ação seja exclusivamente o próprio bem-estar, mas, ao contrário, aceita a recompensa, isto é, o bem-estar como o fruto de um trabalho, por exemplo. Por fim, o humanitarismo permite ver na proibição um auxílio às pessoas dependentes que se beneficiariam, pois não teriam como ceder aos caprichos do próprio vício, assim como ajudaria também os familiares dos dependentes químicos. 
Além das características culturais e religiosas, a xenofobia e o controle social no interior do país contribuíram para que a população dos Estados Unidos vinculasse determinadas drogas a grupos étnicos específicos. Assim, associava-se o álcool aos irlandeses, a maconha aos mexicanos, a cocaína aos negros e o ópio aos chineses (ESCOHOTADO, 1996; FIORE, 2005). Essas relações inseriam na sociedade uma espécie de aversão às drogas, como se elas fossem "males" trazidos de fora do país. Criou-se, assim, a falsa separação entre países produtores de droga - países subdesenvolvidos - e países consumidores - desenvolvidos. Essa divisão é um mito, e cabe ressaltar a existência antiga de plantações de maconha nos parques nacionais estadunidenses, que desmentiram essa convicção que colocava numa situação de vítima países economicamente favorecidos (RODRIGUES, 2005).

As leis proibicionistas, que contrariavam a ideologia do liberalismo altamente difundido na política norte-americana - alcançaram o clímax do puritanismo, em 1919, com a aprovação da $18^{\text {a }}$ Emenda e do Ato Volstead, mais conhecido como Lei Seca, pela qual foi proibida a fabricação, a importação, a comercialização e o uso de bebidas alcoólicas no país (BECKER, 1977; RODRIGUES, 2005). Outra ação semelhante foi o Ato Harisson, que vetou o uso de ópio e de derivados, excetuando-se aqueles para fins médicos (como a morfina). Para esses opiáceos destinados à medicina, eram somadas altas taxas na margem de preços dos fornecedores autorizados (BECKER, 1977).

E, assim, a "onda não-permissiva" foi se alastrando. Becker explica que, por volta de 1920, a população estadunidense era indiferente à maconha, que era uma droga desvalorizada, fumada principalmente pelos mexicanos. Em até 10 anos, a proibição desta droga emergiu e, em 1930, 16 estados já teriam aprovado a lei interdizendo à marijuana. Mais tarde, em 1937, pretendendo extinguir o consumo da erva, o Congresso promulgou a Lei de Taxação da Maconha (BECKER, 1977).

Essa política de redução da demanda via elevação das margens dos preços e repressão ao consumo traçaria as diretrizes da política nacional, resultando na criação de polícias e de agências de controle e de repressão ao comércio de drogas, como o Federal Bureau of Narcotics, criado em 1930, depois substituído pelo Bureau of Drug Abuse Control e pelo Bureau of Narcotics and Dangerous Drugs, na década de 1960 (RODRIGUES, 2005). Esse modelo estadunidense se refletiria aos demais países, sendo representado por órgãos da diplomacia internacional. 
Seguindo esses passos, a Liga das Nações, criada após a I Guerra Mundial e encerrada por volta de 1930, seguida das Organizações das Nações Unidas (ONU), criada a partir da II Guerra Mundial, foram primordiais na documentação relativa à proibição das drogas. Diversas conferências internacionais debateram o tema, sendo a Convenção Única de 1961 a principal delas, pois definiu, por meio de listas, quais drogas seriam permitidas para fins médicos (como a morfina, derivada do ópio) e quais seriam proibidas (como a heroína).

A intenção da Convenção é bem explicada, no preâmbulo, ao direcionar-se às nações nos seguintes termos:

\begin{abstract}
Preocupadas com a saúde física e moral da humanidade; reconhecendo que o uso médico dos entorpecentes continua indispensável para o alívio da dor e do sofrimento e que medidas adequadas devem ser tomadas para garantir a disponibilidade de entorpecentes para tais fins; reconhecendo que a toxicomania é um grave mal para o indivíduo e constitui um perigo social e econômico para a humanidade; conscientes de seu dever de prevenir e combater esse mal; considerando que as medidas contra o uso indébito de entorpecentes, para serem eficazes, exigem uma ação conjunta e universal; julgando que essa atuação universal exige uma cooperação internacional, orientada por princípios idênticos e objetivos comuns; reconhecendo a competência da Nações Unidas em matéria de controle de entorpecente e desejosas de que os órgãos internacionais a ele afetos estejam enquadrados nessa Organização; desejando concluir uma convenção internacional que tenha aceitação geral e venha substituir os trabalhos existentes sobre entorpecentes, limitando-se nela o uso dessas substâncias afins médicos e científicos estabelecendo uma cooperação a uma fiscalização internacionais permanentes para a consecução de tais finalidades e objetivos (BRASIL, 1975, p. 1-2).
\end{abstract}

Neste mesmo período, outras drogas ${ }^{15}$ ganharam força nos EUA ao integrarem o movimento hippie, que contrariava a cultura e o nacionalismo do próprio país ao repudiar a Guerra no Vietnã (e todo o militarismo estadunidense) e defender um estilo de vida que se aliava ao prazer, à liberdade sexual, ao misticismo, à paz e ao amor. A arte psicodélica, que caracterizou os hippies, foi a mais significativa expressão do efeito alucinógeno (e enteógeno) de determinados psicoativos, como o $\mathrm{LSD}^{16}$. Esse ácido foi sintetizado pelo químico Albert Hofmann por volta da década de 1940, embora tenha se popularizado nas décadas de 1960 e 1970. Acredita-se que celebridades do rock, como os Beatles,

\footnotetext{
${ }^{15}$ Há, inclusive, uma música no clássico filme Hair, que faz um retrato do movimento hippie, cuja letra da canção menciona diversas substâncias psicoativas, tais como o DMT, peiote e metanfetamina.

${ }^{16}$ LSD ou LSD-25 (dietilamida do ácido lisérgico).
} 
compuseram músicas descrevendo os efeitos desse psicoativo - a canção Lucy in the Sky with Diamonds é um claro exemplo e já traz no título as siglas do LSD ${ }^{17}$ (ESCOHOTADO, 2002).

Como uma resposta à expansão e à criação de novas drogas, a Comissão de Narcóticos da ONU, estabeleceu, na Convenção sobre Substâncias Psicotrópicas, em 1971, um sistema de controle internacional, separando essas novas substâncias pela capacidade de gerar dependência e de tratamento terapêutico.

Se por um lado a proibição desses produtos pretendia inibir o consumo, por outro implicou numa larga margem do contrabando e do mercado negro. A fim de conter o tráfico e a lavagem de dinheiro, a Convenção contra o Tráfico Ilícito de Drogas Narcóticas e Substâncias Psicotrópicas, organizada em 1988, pela ONU, estipulou medidas para resolver esse problema que, ao que tudo indica, se tornou mais grave que o consumo ${ }^{18}$.

Ao falar das imposições sociais, Howard Becker explica que os valores não criam automaticamente regras e comenta: "Porque uma regra pode satisfazer a um interesse e ainda assim entrar em conflito com outros interesses do grupo que a faz, em geral toma-se cuidado, ao formular uma regra, em garantir que ela só realizará o que se espera dela e nada mais.” (BECKER, 1977, p. 95). Contudo, não foi possível assegurar que as regras de proibição do comércio e do consumo de drogas realizassem apenas a inibição ou o fim do consumo. Resultado colateral não esperado, a repressão criou um novo problema: o narcotráfico.

O avanço neoliberal, a partir da década de 1970, acarretou uma série de transformações nos cenários econômicos internacionais, marcando o início de um período de instabilidades macroeconômicas. O enfraquecimento do Estado na promoção do Welfare State e das regulações na economia somado aos avanços das tecnologias de informação que conformam a III Revolução Industrial fizeram emergir a insegurança e a vulnerabilidade no mercado de trabalho, percebidas pelo enfraquecimento dos sindicatos e pelo aumento do desemprego (MATTOSO, 1995). A concentração e a centralização do capital nas grandes empresas oligopolísticas representaram o avanço do capital financeiro no predomínio da

\footnotetext{
${ }^{17}$ Outro exemplo é a música Come Together, homenagem ao psiquiatra Thimothy Leary, um dos principais divulgadores do ácido, que defendia o uso irrestrito, isto é, não apenas para tratamentos psiquiátricos ou oncológicos. Leary era professor de Harvard e foi expulso da Universidade ao realizar uma experiência prática, usando o entorpecente, com estudantes de uma turma inteira.

${ }^{18}$ O Decreto 162, de 1991, aprova no Brasil o texto desta Convenção.
} 
economia mundial, que, frente à emergência dos ideais neoliberais, rompeu fronteiras e intensificou o fenômeno da globalização (SILVA, 2010).

A globalização, por sua vez, impactou significativamente no mercado de drogas, pois, ao mesmo tempo em que se deram as aberturas de mercados formais, também se abriram os mercados ilegais. O aumento da concorrência em nível mundial, a redução da regulamentação financeira e a elevação das transações entre países intensificaram o mercado de drogas e reforçaram a degradação das questões sociais, agravando a situação da população pobre dos países desenvolvidos e elevando a criminalidade e a marginalização das populações dos países do terceiro mundo, ou seja, aumentando a desigualdade, deixando "os ricos mais ricos e os pobres mais desesperados" (WOODIWISS, 2007, p. 218). A própria globalização no mercado financeiro impactou no narconegócio. Conforme explica Woodiwiss, "a tendência à globalização dos mercados financeiros ao longo das décadas recentes foi acompanhada pelo rápido crescimento de três tipos de atividade financeira ilícita” (2007, p. 239), que são a evasão fiscal, a fuga de capitais e a lavagem de dinheiro. Essa última foi favorecida pelo acentuado descontrole e não acompanhamento das transações financeiras e comerciais no âmbito internacional, favorecendo a prática de limpar dinheiro "sujo" na grande "máquina" de investimentos denominada mercado financeiro - além de viabilizar a segurança monetária do criminoso, também possibilitou o aumento e a acumulação de lucros. Conforme argumenta Souza (2007):

O sentido do aumento da ilegalidade na sociedade contemporânea deve ser entendido com base nas transformações recentes do capitalismo: no que tange ao problema do emprego e da perda de coesão social, responsável por elementos como a "integração perversa" ao mercado de trabalho e superexploração da mão de obra [...]; e o surgimento de novas oportunidades para o crime global, que vai se beneficiar da redução de barreiras tarifárias, desregulamentação dos mercados de trabalho e financeiro, advento de novas tecnologias e de uma profunda capacidade de se adaptar às recentes exigências de flexibilidade (SOUZA, 2007, p. 87).

Portanto, pode-se compreender o agravamento da questão das drogas na transformação do sistema capitalista, via intensificação dos processos de concentração e de centralização do capital ${ }^{12}$, cuja busca inexorável por acumulação de capital configura a lógica que motiva os agentes e os mercados. O entendimento dessa racionalidade econômica por trás dos comportamentos, bem como o 
reconhecimento do crescimento das desigualdades, da pobreza, do desemprego e da insegurança no cenário econômico moderno, devido ao advento do avanço neoliberal, que tanto afetou o consumo, o tráfico e, ainda, o Estado, são cruciais para compreender o mercado de drogas.

\section{O comércio global da droga na contemporaneidade}

O acompanhamento do mercado global de drogas ilícitas permite a avaliação de dados e de estimativas do número de usuários e da prevalência do uso em um período, bem como de cultivo, de produção e de preços das mercadorias, ou seja, os dados sobre os consumidores e os traficantes permitem obter informações aproximadas sobre demanda e oferta de drogas. A análise dos valores desse mercado é um importante instrumento que permite identificar o fluxo e a dinâmica dessas trocas comerciais, além de ser útil na orientação de políticas sobre drogas.

Segundo o relatório Estimating Illicit Financial Flows Resulting From Drug Trafficking and Other Transnational Organized Crimes, de 2011, o crime organizado teria gerado, em 2009, o correspondente a 1,5\% do PIB mundial, sendo o narcotráfico a atividade criminal transnacional com maior rentabilidade (UNODC, 2011a). Em 2003, o mercado global de psicoativos ilegais foi estimado em 12,8 bilhões de dólares a preço de produção, em 94 bilhões de dólares a preço no atacado e em 321,6 bilhões de dólares a preço no varejo. Esse último valor corresponde a quase $1 \%$ do PIB global ${ }^{19}$ do mesmo ano, além de superar o PIB de $88 \%$ dos países avaliados ${ }^{20}$ pelo World Bank (UNODC, 2005).

Essas estimativas foram calculadas a partir do trabalho desenvolvido pela United Nations Office on Drugs and Crime (UNODC), com base na união de informações disponibilizadas por diversos países do mundo. Fundada em 1997, a UNODC é um departamento da Organização das Nações Unidas, responsável pelo enfrentamento do tráfico de drogas, de armas, de pessoas, de animais e de recursos naturais, bem como do terrorismo e de outros tipos de crime, como os cibernéticos. O órgão trabalha a partir de projetos de cooperação técnica, de pesquisas e análises e de trabalhos normativos, que buscam auxiliar, orientar, levantar evidências e compreender as problemáticas das drogas e do crime, a fim de auxiliar na

\footnotetext{
${ }^{19}$ Valor baseado nos cálculos do Banco Mundial.

${ }^{20}$ Corresponde a 163 dos 184 países acompanhados pelo Banco Mundial.
} 
implementação de normas e de políticas nos países membros da ONU. Com relação especificamente às drogas, a UNODC publica anualmente o World Drug Report, um relatório com informações sobre rotas do narcotráfico e estimativas sobre a demanda e a oferta do mercado de drogas.

Até meados da década de 1990, a escassez de informações sobre o mercado de drogas era um empecilho ao desenvolvimento e à ampliação de pesquisas e de estudos científicos. Ao abordar a questão de informações e de estimativas na França, Kopp (1998) apontou para o problema das estatísticas, cujo foco era demasiadamente centrado nos dependentes químicos, ignorando, muitas vezes, os consumidores ocasionais. $\mathrm{O}$ autor também identifica algumas incoerências em dados de diferentes instituições de um mesmo país, problema comum nas informações referentes às drogas, nas décadas de 1980 e 1990, que ainda permanece, em menor grau, até hoje.

A partir do fim da década de 1990, com a elaboração de relatórios anuais pela UNODC, pôde-se construir uma base de estimativas mais padronizadas e mais consistentes, devido ao acompanhamento da instituição junto aos países-membros da ONU. Nesse sentido, os estudos apresentados pela UNODC tornam-se importantes ferramentas no acompanhamento das mudanças e da dinâmica desse comércio global.

Entretanto, é importante destacar a tendência da UNODC de classificar os países subdesenvolvidos como produtores e os países desenvolvidos como consumidores de drogas. Essa distinção originou-se nos Estados Unidos e foi utilizada como um pretexto à expansão do imperialismo e à intervenção militar na América Latina (PASSETTI, 1991), já que transferia a culpa da problemática das drogas a outros países - os produtores. Essa qualificação posicionava os Estados Unidos como vítima, tendo em vista que os governantes desse país, ao projetarem a origem do mal das drogas às relações exteriores, ignoravam uma série de cultivos ilícitos que existiam no próprio território, como as plantações de Cannabis em parques nacionais e estaduais (PASSETTI, 1991; RODRIGUES, 2005). Apesar dessas observações quanto à influência e à parcialidade na classificação dos relatórios, ainda assim, os dados podem ser importantes ferramentas ao estudo da Economia das Drogas.

O mercado global de drogas ilícitas tem se mantido estável na última década. Apesar do pequeno aumento do número de consumidores, este 
incremento é proporcional ao crescimento da população mundial. Conforme o World Drug Report de 2014, estima-se que 243 milhões de pessoas tenham usado algum tipo de substância psicoativa ilícita no ano de 2012, podendo esse número variar entre 162 a 324 milhões de consumidores. Isso implica uma proporção de $5,2 \%$ da população global da faixa de 15 a 64 anos. No início do século XXI, o número de indivíduos que fizeram uso de algum tipo de psicoativo ficou na faixa de 185 milhões de pessoas, ou seja, 4,7\% da população entre 15 a 64 anos. A Tabela 1 apresenta a quantidade de consumidores no mundo e a prevalência anual de uso na população.

Tabela 1 - Estimativa de usuários de drogas ilícitas no mundo, em número e em proporção (2000-2012)

\begin{tabular}{|c|c|c|c|c|c|c|c|c|c|c|c|c|}
\hline & $\begin{array}{r}2000- \\
2001\end{array}$ & $\begin{array}{r}2001- \\
2003\end{array}$ & $\begin{array}{l}2003- \\
2004\end{array}$ & 2004 & 2005 & 2006 & 2007 & 2008 & 2009 & 2010 & 2011 & 2012 \\
\hline $\begin{array}{l}\text { Nde usuários (em } \\
\text { milhões) ......................... }\end{array}$ & 200 & 185 & 200 & 200 & 200 & 208 & 211 & 203 & 210 & 226 & 240 & 243 \\
\hline $\begin{array}{l}\text { Proporção pop. 15-64 } \\
\text { anos (em \%) ............. }\end{array}$ & $4,7 \%$ & $4,7 \%$ & $5,0 \%$ & $4,9 \%$ & $4,8 \%$ & $4,9 \%$ & $4,9 \%$ & $4,6 \%$ & $4,8 \%$ & $5,0 \%$ & $5,2 \%$ & $5,2 \%$ \\
\hline
\end{tabular}

Fonte: UNODC (2003, 2004, 2005, 2006, 2007, 2014). Elaboração própria.

O relatório também aponta que, embora pouco mais desses 5\% da população esteja estimada como usuário de substância psicoativa, esse dado não implica, necessariamente, consumidores regulares, mas apenas que consumiram alguma droga ilícita nos últimos 12 meses. Com relação ao uso abusivo ou problemático, o número de usuários foi estimado em torno de 27 milhões de pessoas (0,6\% da população de 15 a 64 anos).

Quando observado o uso por grupo de droga, constata-se que a mais consumida é a Cannabis. Os dados mais recentes apresentam um número de 177,3 milhões de usuários deste tipo de droga. Em segunda posição, encontramse as anfetaminas, com 34,4 milhões de usuários. Em seguida, estão os opióides, com 33,04 milhões de usuários; seguidos do ecstasy, com 18,75; da cocaína, com 17,24 e, por último, dos opiáceos, com 16,37 milhões de consumidores. Alertase aqui para o poliuso de psicoativos, ou seja, um usuário de um grupo de substância pode ser contabilizado também como usuário de outro grupo. A Tabela 2 apresenta os números de usuários e de proporção da população entre 15 e 64 anos desses grupos de psicoativos. 
Tabela 2 - Uso de psicoativos ilícitos na população global, por grupo de droga, em número de usuários e em proporção da população entre 15-64 anos (2012)

\begin{tabular}{lcc}
\hline & $\begin{array}{c}\mathbf{N}^{\circ} \text { de usuários* } \\
\text { (em milhões) }\end{array}$ & $\begin{array}{c}\text { Proporção pop. } \\
\text { 15-64 anos (em \%) }\end{array}$ \\
\hline Cannabis ............ & 177,63 & $3,80 \%$ \\
Anfetaminas ....... & 34,40 & $0,70 \%$ \\
Opióides $* * \ldots . . . . .$. & 33,04 & $0,70 \%$ \\
Ecstasy ................ & 18,75 & $0,40 \%$ \\
Cocaína ............... & 17,24 & $0,37 \%$ \\
Opiáceos ............ & 16,37 & $0,35 \%$ \\
\hline
\end{tabular}

Nota: * Considerando o poliuso de psicoativos, de modo que um usuário pode ser contabilizado em mais de um grupo. ** Conjunto de substâncias psicoativas sintéticas derivadas do ópio.

Fonte: UNODC (2014). Adaptado.

O Gráfico 2, que apresenta os valores gerados na economia por tipo de droga, diferencia-se da ordem de classificação de número de consumidores (Tabela 2). Em parte, isso ocorre devido à diferença de preço de um psicoativo para outro. Isso indica um consumo maior ou menor conforme o contexto do consumidor. Por outro lado, o indicador do número de usuários revela a prevalência do uso anual, ou seja, o número de consumidores que usou determinada droga no ano anterior. Assim, a demanda de determinado tipo de substância pode gerar maiores receitas consoante as quantidades consumidas e não necessariamente à quantidade de consumidores.

Os dados acerca dos valores gerados na economia global pelo comércio varejista de drogas ilícita indicam um total de 322 bilhões de dólares para o ano de 2003. O grupo com maior receita foi a maconha, que movimentou 113 bilhões de dólares naquele ano, seguido pela cocaína, com 71 bilhões de dólares, pelos opiáceos com US\$ 65 bilhões, pelas anfetaminas, com US\$ 44 bilhões e, por último, pelo haxixe, com US\$29 bilhões. 
Gráfico 2 - Valor gerado no mercado global de psicoativos ilícitos, por grupo de droga, em bilhões de US\$ - 2003

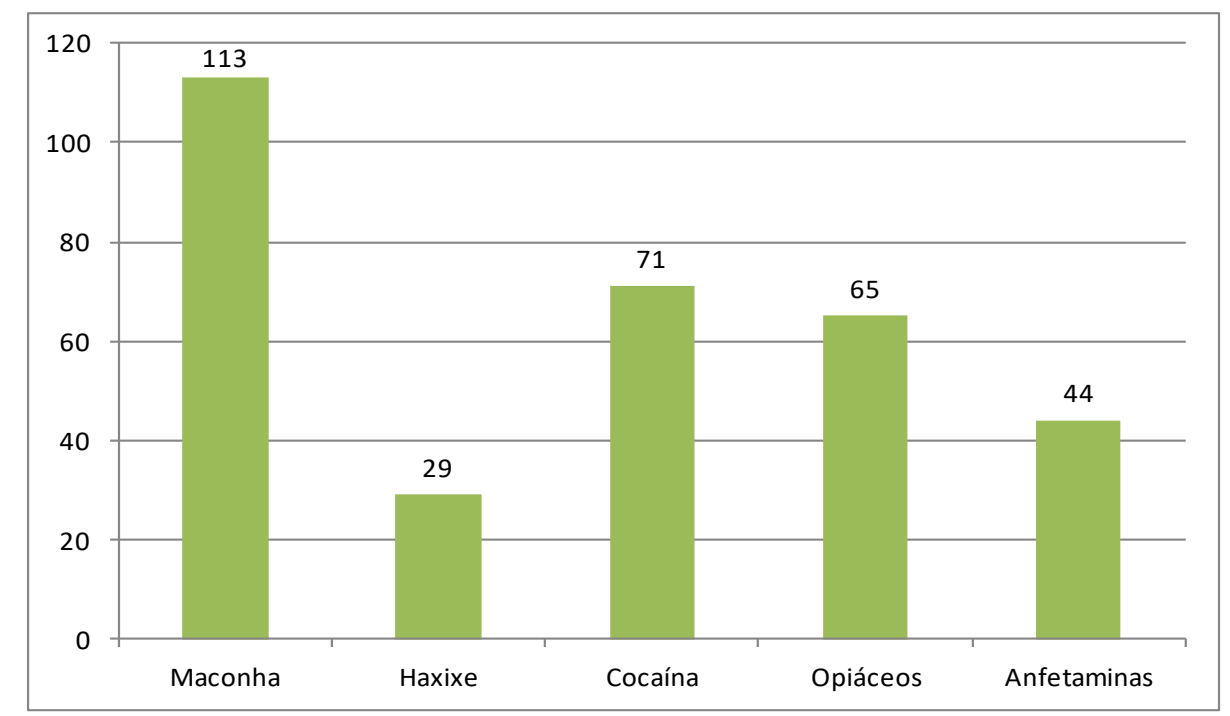

Fonte: UNODC (2005). Elaboração própria.

Desse montante, a Cannabis representou, para o ano de 2003, uma participação de quase a metade do valor gerado no mercado global, com 44,1\%, sendo $35,1 \%$ para a erva (maconha) e $9 \%$ para a resina da planta (haxixe). Ao analisarmos pelo tamanho do mercado consumidor, essa participação é maior ainda, pois abrange cerca de $74 \%$ dos consumidores de psicoativos no mundo. No caso da cocaína, estimou-se uma participação de $22 \%$ em valor gerado na economia e $6 \%$ no volume da demanda de drogas. Os opiáceos participam com $20,2 \%$ em valor e $7 \%$ em consumo; e as anfetaminas, com $13,7 \%$ em valor e $12 \%$ em mercado consumidor. A Erro! Fonte de referência não encontrada. apresenta esses dados para comparação. 
Tabela 3 - Valor gerado no mercado global de psicoativos, número de usuários e participações percentuais, por grupo de droga, em US\$, em milhões de pessoas e em \% (2003)

\begin{tabular}{lcccc}
\hline & $\begin{array}{c}\text { Valor } \\
\text { (em US\$ bilhões) }\end{array}$ & $\begin{array}{c}\text { Participação } \\
\text { (em \%) }\end{array}$ & $\begin{array}{c}\mathbf{N}^{\circ} \text { de usuários* } \\
\text { (em milhões) }\end{array}$ & $\begin{array}{c}\text { Participação } \\
\text { (em \%) }\end{array}$ \\
\hline Cannabis & 142 & $44,1 \%$ & 160,9 & $74,2 \%$ \\
Cocaína & 71 & $22,0 \%$ & 13,73 & $6,3 \%$ \\
Opiáceos* & 65 & $20,2 \%$ & 15,94 & $7,4 \%$ \\
Anfetaminas & 44 & $13,7 \%$ & 26,16 & $12,1 \%$ \\
Total & $\mathbf{3 2 2}$ & $\mathbf{1 0 0 , 0 \%}$ & $\mathbf{2 1 6 , 7 3}$ & $\mathbf{1 0 0 , 0 \%}$ \\
\hline
\end{tabular}

Nota: * A UNODC não disponibilizou para esse período informações sobre o mercado de opióides. ** Inclui "dupla contagem" associada ao poliuso de parte do mercado consumidor. Fonte: UNODC (2005). Elaboração própria.

Quando observadas as regiões do globo, também são encontradas algumas diferenças. Na África, a substância psicoativa mais utilizada é a maconha, especialmente na região ocidental do continente, com uma prevalência de uso de $7,5 \%$, ou seja, praticamente o dobro da média do uso global. O segundo tipo de substância mais consumida é a anfetamina com $0,9 \%$ de prevalência, seguida pela cocaína com $0,4 \%{ }^{21}$ e pelos opiáceos com $0,3 \%$ (UNODC, 2013). No continente americano, com exceção dos opiáceos, todos outros grupos de substâncias ilícitas apresentam consumos acima da média global. Na América do Norte, a Cannabis é a substância mais usada e apresenta uma prevalência de uso de 7,9\%; em segunda posição, está a cocaína, com prevalência de 1,3\%. Na América Latina e Caribe, a maconha também apresentou a maior prevalência de uso, com diferenças consideráveis entre a América do Sul e a América Central e Caribe, com índices de 5,7\%, 2,6\% e 2,8\%, respectivamente. No Relatório de 2013, destacou-se a elevação do consumo do grupo "cocaína" (incluindo derivados, como o crack) nos países Brasil, Costa Rica e Peru. Na Europa, o cânhamo também é a substância mais consumida (prevalência de uso de 5,6\%), sendo a cocaína a segunda, os opióides a terceira e as anfetaminas a quarta, com prevalências de $0,8 \%, 0,7 \%$ e $0,5 \%$, respectivamente. A prevalência do uso da Cannabis praticamente dobra quando avaliada a Oceania, cujos consumidores consolidam 10,9\% da população entre 15 e 64 anos. Nesse continente, o uso de psicoativos é mais intenso, sendo a prevalência de uso de opióides de $3 \%$, de ecstasy $2,9 \%$, de anfetaminas $2,1 \%$ e de

\footnotetext{
${ }^{21}$ O número de usuários de cocaína na África Ocidental e Central é estimado em 1,6 milhão de pessoas, sendo a Nigéria o país com maior consumo de cocaína e de heroína no continente.
} 
cocaína 1,5\%. Finalmente, a Ásia revela um importante mercado consumidor, concentrando em torno de 25 a $40 \%$ de todos consumidores mundiais de drogas ilegais. Além disso, o continente asiático concentra $60 \%$ dos consumidores de opiáceos do planeta. Embora a prevalência de uso de Cannabis na região seja relativamente baixa $(1,9 \%)$, quando comparadas às proporções das outras regiões globais, a Ásia apresenta o maior consumo do cânhamo, em números absolutos (53,3 milhões de usuários) (UNODC, 2013, 2014).

Finalmente, sobre as técnicas de transporte e de tráfico de mercadorias ilícitas, as informações sobre apreensões ${ }^{22}$ podem significar mudanças nas rotas ou no manuseio das mercadorias. Assim, considerando os principais meios de transporte, o que carrega maiores quantidades de drogas por viagem é o marítimo. Em geral, as apreensões em navios e submarinos não superam 11\% do total das ações policiais; entretanto, é possível apreender maiores quantidades de psicoativos, já que, em média, são confiscadas 30 vezes mais quantidades de droga em transporte marítimo que aéreo. Ademais, algumas operações contra o tráfico conseguem identificar o país de proveniência da mercadoria, que pode ser um país de produção ou de trânsito da droga. O Brasil, por exemplo, é considerado o principal país de trânsito da cocaína, já que as vastas fronteiras terrestres e marítimas permitem que a substância seja despachada a outros continentes. O Quadro 1 reúne os principais países mencionados em apreensões realizadas no período 2001 a 2012.

\footnotetext{
${ }^{22}$ Geralmente, as informações sobre quantidades de drogas apreendidas são utilizadas na avaliação da eficiência das políticas de segurança pública e, portanto, implicam disputas políticas e governamentais. Assim, este trabalho evitou a exposição quantitativa destas informações por duas razões: 1) os dados sobre quantidades apreendidas não interferem diretamente no volume do comércio global, já que não se pode saber a proporção do que é apreendido versus o que circula; 2) essas informações entram no jogo das disputas políticas, especialmente quando são usados aumentos de apreensões como dados de eficiência policial, o que pode não apenas ser uma conclusão equivocada, quanto errônea, seguindo a lógica do mercado de drogas.
} 
Quadro 1 - Proveniência de países, segundo as principais apreensões individuais, por tipo de drogas

(incluindo todos os meios de transporte) - 2001-2012

\begin{tabular}{|c|c|c|c|}
\hline & Cocaína* & Heroína & Cannabis \\
\hline 1 & Brasil & Afeganistão & Marrocos \\
\hline 2 & Colômbia & Paquistão & Afeganistão \\
\hline 3 & Argentina & Tajiquistão & Jamaica \\
\hline 4 & República Dominicana & Albânia & Holanda \\
\hline 5 & Venezuela & Turquia & África do Sul \\
\hline 6 & Peru & Holanda & Paraguai \\
\hline 7 & Jamaica & Irã & Gana \\
\hline 8 & Bolívia & Índia & Espanha \\
\hline 9 & Costa Rica & Tailândia & Nepal \\
\hline 10 & Holanda & Quirguistão & Albânia \\
\hline 11 & Equador & Bélgica & Argélia \\
\hline 12 & México & Bulgária & Moçambique \\
\hline 13 & Panamá & Cazaquistão & Paquistão \\
\hline 14 & Nigéria & Alemanha & Honduras \\
\hline 15 & Gana & Nigéria & Índia \\
\hline 16 & Espanha & Grécia & Irã \\
\hline 17 & Guiné & Uzbequistão & Cazaquistão \\
\hline 18 & Chile & Mianmar & Haiti \\
\hline 19 & Senegal & Espanha & Estados Unidos \\
\hline 20 & Trinidad e Tobago & Hong Kong, China & França \\
\hline
\end{tabular}

Fonte: UNODC (2013). Adaptado.

\section{Considerações finais}

$\mathrm{O}$ presente artigo possibilitou o entendimento e o aprofundamento da problemática questão das drogas, ultrapassando o ponto de vista social e comprovando a nítida relação com a economia e demais áreas do conhecimento.

O resgate da história das drogas conectou os valores que esses produtos representavam para o homem às transformações políticas, econômicas e sociais ocorridas. Observa-se que o significado atribuído aos psicoativos acompanhou, desde sempre, o cenário mundial. Do valor de uso à mercadoria ilegal, ocorreram muitas mudanças, apesar de alguns hábitos pontuais permanecerem, como a prevalência de algumas drogas em culturas específicas ou em rituais religiosos, como a ayahuasca, bem como em hábitos sociais, como o álcool.

Também foi possível compreender a relação da droga com o homem, pois a necessidade de sociabilizar e de abstrair sempre existiu. O que separa o uso de 
drogas nas festas pelos povos primitivos dos contemporâneos é a permissão ou não do uso. Com a proibição, alguns psicoativos foram excluídos do círculo social, mas o consumo de drogas lícitas, como o álcool, continua sendo usado como instrumento de aproximação das pessoas; enquanto o uso de tóxicos ilícitos passou a ser instrumento de exclusão de indivíduos.

Do mesmo modo, a análise histórica mostrou que as drogas passaram a representar um problema maior quando se transformaram em mercadoria. As disputas por mercados consumidores e por domínio da produção iniciaram os primeiros conflitos relacionados a esses bens. $\mathrm{O}$ avanço da indústria química e farmacêutica também contribuiu consideravelmente para a disseminação do consumo, refletindo nas competições entre Estados Unidos e Europa, ao longo dos séculos XIX e XX.

Pela revisão histórica da formação desse mercado, notou-se que, passando do movimento hippie das décadas de 1960 e 1970 até o período atual, o consumo de drogas não cessou, o crime organizado tomou dimensões transnacionais e as questões sociais se agravaram, especialmente pela violência inerente à ilegalidade desse mercado. Ainda que o proibicionismo mostre-se, em um primeiro momento, incoerente aos ideais do liberalismo econômico, em um segundo momento, o proibicionismo viabiliza a expansão dos lucros, principalmente diante dos Estados enfraquecidos. Essas evidências estão, atualmente, levando muitos países a questionarem suas políticas sobre as drogas.

Ademais, ficou clara a influência do preço no consumo de psicoativos. Como o crack, o ópio também foi considerado uma epidemia pela rapidez do crescimento do número de usuários atribuída ao aumento da oferta e da redução do preço. Ao contrário, a cocaína não se popularizou em nenhum momento devido ao alto custo.

O trabalho também mostrou que é possível calcular estimativas do comércio e do consumo mundial. Esses dados podem ser importantes agregadores às políticas públicas, pois permitem visualizar as tendências do mercado ilegal no mundo todo. Para alguns psicoativos, como o crack e a maconha, torna-se mais difícil a obtenção dessas informações, já que a transformação da pasta-base de coca em "pedra" não pode ser acompanhada por satélites ou por inspeções locais, visto que a produção é mais caseira, assim como o cultivo indoor da Cannabis. 
Por fim, ressalta-se que pesquisas sobre drogas possibilitam entender os mecanismos da demanda e da oferta que podem ser alterados - ou não - por intervenções governamentais. Essa é a principal contribuição que a Ciência Econômica pode dar neste tema, que é interdisciplinar.

\section{Referências}

A DOUTRINA da Floresta. O que é nossa religião? Disponível em: http://www. santodaime.org/doutrina/oquee.htm. Acesso em: 26/01/2011.

ADIALA, J. C. A criminalização dos entorpecentes. Rio de Janeiro: IUPERJ, 1996.

BECKER, H. S. Uma Teoria da Ação Coletiva. Rio de Janeiro: Zahar Editores, 1977.

BRASIL. Senado Federal. Decreto $\mathrm{n}^{\circ}$ 76.248, de 12 de setembro de 1975. Disponível em: http://www.obid.senad.gov.br/portais/Internacional/biblioteca/ documentos/links/Onu/convencoes/327097.pdf.

CÁRCERES, F. História Geral. São Paulo: Moderna, 1996.

CARNEIRO, H. Transformações do significado da palavra "droga": das especiarias coloniais ao proibicionismo contemporâneo. In: VENÂNCIO, R. P.; CARNEIRO, H. (Orgs.). Álcool e drogas na história do Brasil. São Paulo: Alameda; Belo Horizonte: Editora PUCMinas, 2005.

DOMANICO, A. Craqueiros e cracados: bem-vindo ao mundo dos nóias! Estudo sobre a implementação de estratégias de redução de danos para usuários de crack nos cinco projetos-piloto do Brasil. 2006. 220 p. Tese (Doutorado em Ciências Sociais). Programa de Pós-Graduação em Ciências Sociais, da Faculdade de Filosofia e Ciências Humanas, Universidade Federal da Bahia, Salvador.

ENGELS, F. A situação da classe trabalhadora na Inglaterra. Porto: Afrontamento, [1845] 1975.

ESCOHOTADO, A. Historia General de Las Drogas. 3. v. Madri: Alianza, 1995.

ESCOHOTADO, A. Historia Elemental de Las Drogas. Barcelona: Anagrama, 1996.

ESCOHOTADO, A. Historia General de Las Drogas - incluyendo El apêndice "Fenomenología de lás Drogas". Madrid: Espasa Calpe, 2002. 
FERREIRA, A. B. H. Miniaurélio Século XXI: o minidicionário da língua portuguesa. Rio de Janeiro: Nova Fronteira, 2000.

FIORE, M. A medicalização da questão do uso de drogas no Brasil: reflexões acerca de debates institucionais e jurídicos. In: VENÂNCIO, Renato Pinto; CARNEIRO, Henrique (Org.). Álcool e drogas na história do Brasil. São Paulo: Alameda; Belo Horizonte: Editora PUCMinas, 2005.

GOOTENBERG, P. Cocaine: global histories. Londres: Routledge, 1999.

GOOTENBERG, P. Andean cocaine: the making of a global drug. Durham: The University of North Carolina Press, 2008.

KARCH, S. B. A history of cocaine: the mystery of coca java and the new plant. Londres: Royal Society of Medicine Press, 2003.

KOPP, P. A economia da droga. Bauru: EDUSC, 1998.

KOUTOUZIS, M.; PEREZ, P. Atlas Mondial des Drogues. Paris: Presses Universitaires de France, 1997.

LEITE, M. C.; ANDRADE, A. G. Cocaína e Crack - Dos Fundamentos ao Tratamento. Porto Alegre: ARTMED, 1999.

LENOIR, R. Objeto Sociológico e Problema Social. In: CHAMPAGNE et al. Iniciação à prática sociológica. Petrópolis: Vozes, 1998.

LIMA, R. C. C. Uma história das drogas e do seu proibicionismo transnacional: relação Brasil-Estados Unidos e os organismos internacionais. 2009. 365 f. Tese (Doutorado em Serviço Social) - Programa de Pós-Graduação em Serviço Social, Escola de Serviço Social, Universidade Federal do Rio de Janeiro

MacRAE, E. Guiado pela Lua: Xamanismo e uso ritual da ayahuasca no culto do Santo Daime. São Paulo: Brasiliense, 1992.

MARX, K. O capital. Rio de Janeiro: Livros Técnicos e Científicos, 1982.

MATTOSO, J. A desordem do trabalho. São Paulo: Scritta, 1995.

NEVINNÝ, J. The Coca Leaf - A pharmacognostic tretise. In: KARCH, S. B. A history of cocaine: the mystery of coca java and the new plant. Londres: Royal Society of Medicine Pr Ltd, 2003. 
PASSETTI, E. Das fumeries ao narcotráfico. São Paulo: EDUC, 1991.

RODRIGUES, T. Narcotráfico: um esboço histórico. In: VENÂNCIO, R. P.; CARNEIRO, H. (Org.). Álcool e drogas na história do Brasil. São Paulo: Alameda; Belo Horizonte: Editora PUCMinas, 2005.

SCHILLING, V. Estados Unidos e América Latina: da Doutrina Monroe à ALCA. Porto Alegre: Leitura XXI, 2002.

SILVA, A. L. G. Concorrência sob condições oligopolísticas: contribuição das análises centradas no grau de atomização/concentração dos mercados. Campinas: Unicamp, 2010.

SOUZA, M. B. Capitalismo e clandestinidade: os subcircuitos ilegais da economia urbana metropolitana. 2007. (Dissertação) Mestrado em Desenvolvimento Econômico - Área de concentração: Economia Regional e Urbana. Instituto de Economia. Universidade Estadual de Campinas.

UNODC - United Nations Office on Drugs and Crime. Global Illicit Drug Trends 2003. Viena: United Nations Publication, 2003.

UNODC - United Nations Office on Drugs and Crime. World Drug Report 2004. Viena: United Nations Publication, 2004.

UNODC - United Nations Office on Drugs and Crime. World Drug Report 2005. Viena: United Nations Publication, 2005.

UNODC - United Nations Office on Drugs and Crime. World Drug Report 2006. Viena: United Nations Publication, 2006.

UNODC - United Nations Office on Drugs and Crime. World Drug Report 2007. Viena: United Nations Publication, 2007.

UNODC - United Nations Office on Drugs and Crime. World Drug Report 2008. Viena: United Nations Publication, 2008.

UNODC - United Nations Office on Drugs and Crime. Estimating Illicit Financial Flows Resulting From Drug Trafficking and Other Transnational Organized Crimes. Viena: United Nations Publication, 2011.

UNODC - United Nations Office on Drugs and Crime. World Drug Report 2013. Viena: United Nations Publication, 2013. 
UNODC - United Nations Office on Drugs and Crime. World Drug Report 2014. Viena: United Nations Publication, 2014.

WOODIWISS, M. Capitalismo Gângster: quem são os verdadeiros agentes do crime organizado. Rio de Janeiro: Ediouro, 2007. 